\title{
Hospital Managers' Perceptions Regarding Setting Healthcare Priorities in Kuwait
}

\author{
Abdullah M. Alsabah ${ }^{1,2}$, Hassan Haghparast-Bidgoli ${ }^{1} \&$ Jolene Skordis-Worrall $^{1}$ \\ ${ }^{1}$ Institute for Global Health, University College London (UCL), UK \\ ${ }^{2}$ Medical Services Authority, Ministry of Defence, Kuwait \\ Correspondence: Abdullah M. Alsabah, Mesillah, block 7, street number 6, house number 45, Kuwait, 22001. \\ E-mail: abdullah.alsabah.14@ucl.ac.uk
}

Received: June 8, 2020 Accepted: July 22, 2020 Online Published: August 4, 2020

doi:10.5539/gjhs.v12n10p79

URL: https://doi.org/10.5539/gjhs.v12n10p79

\begin{abstract}
Background and Objective: In view of the budget limitations resulting from the downturn in the Kuwaiti economy, it is crucial to evaluate the process of priority setting within the health system to identify strengths and weaknesses of this process within both the public and private sectors. Once the weak points are identified, policy makers can work with hospital administration staff to upgrade the process with the aim of utilising health resources more efficiently. The purpose of this study is to give decision makers some insight on the perspective of hospital managers regarding the current process of priority setting, and suggest ways to improve this process. Additionally, this study will provide the opinions of hospital managers in questioning the effect of certain healthcare policies, currently given top priority, on healthcare system efficiency. The views of the hospital managers interviewed indicate their preferences in priority setting and the changes in health spending they believe are required.
\end{abstract}

Methods: A qualitative study was conducted using semi-structured, face-to-face interviews with 14 managers from public and private hospitals in Kuwait. Content analysis was used to produce major themes and sub-themes from the interview transcripts.

Results: While several similarities and differences in the priority-setting process between the public and private sectors were apparent, the main strength in the process that most managers from both sectors mentioned, was that it was simple, systematic, comprehensive and democratic. The several weaknesses of the process include it not being evidence-based due to the lack of accurate and up-to-date data. Also, the discrepancy between the official statements made and the actual practices of health decision makers in the country demonstrate the confusion around the priority-setting process. Most respondents, from both sectors, thought that the availability of a clear and well-communicated national health strategic plan would facilitate the necessary modifications in legislative, structural and administrative strategies to streamline the processes of allocating resources and setting priorities. For example, most respondents believed that the disadvantages of the costly practice of sending patients abroad for treatment and its effect on resource allocation outweighed its advantages. Further, the managers from both sectors had different perceptions regarding the policy of private health insurance for retirees. These two policies, according to some hospital managers, added strain to the health budget and undermined trust in the public-health sector.

Conclusion: This study examined the perspective of hospital managers regarding the process of healthcare priority setting in Kuwait, and ways to improve it. Priority setting could be improved by having a better understanding of its strengths and weaknesses. The study concludes that health decision makers should remain responsible for accepting and implementing evidence-based, systematic processes of resource allocation. Additionally, continuous monitoring and evaluation of the impact of health policies will be required to improve overall health outcomes.

Keywords: priority setting, resource allocation, hospital managers, efficiency, Kuwait

\section{Introduction}

The health system in Kuwait is challenged by a continuous increase in the health budget, coinciding with significant and continuing budget deficits due to lower oil prices (Kuwait Life Sciences Company [KLSC], 2016). This had a direct effect on healthcare because public health expenditures made up around $86 \%$ of total health 
expenditure in the country (World Bank, 2017). To provide long-term fiscal sustainability, the authorities have identified some streamlining options that would reduce spending inefficiencies, improve procurement processes, and facilitate repriotisation of spending (International Monitary Fund [IMF], 2017).

Priority setting, also known as resource allocation (Sibbald, Singer, Upshur, \& Martin, 2009), exists in all healthcare systems where choices must be made on allocating resources between competing services (Ham, 1997; Guindo et al., 2012; Gibson, Martin, \& Singer, 2004; Gibson, Mitton, Martin, Donaldson, \& Singer 2006; Eichler, Kong, Gerth, Mavros, \& Jönsson, 2004; Eddama \& Coast, 2008). It is an essential multi-disciplinary task that involves ethics (transparency and fairness), economics (efficient use of scarce resources to maximise health gains), political science, epidemiology and other disciplines (Guindo et al., 2012; Gibson et al., 2006; Smith et al., 2013; Clark \& Weale, 2012; Gibson, Martin, \& Singer 2005; Otim, Kelaher, Anderson, \& Doran 2014; Husain, Kadir, \& Fatmi, 2007). Priority setting challenges both publicly funded (Ham, 1997; Eichler et al., 2004) and privately funded health systems (Martin \& Singer, 2003). The process is continuous, complex and challenging to all decision makers at all levels, and becomes even more complicated because of the limited interaction and communication among these decision makers regarding resource allocation (Sibbald et al., 2009).

Decisions related to resource allocation in the health sectors of other countries were usually based on historical patterns (Smith et al., 2013; Mitton \& Donaldson, 2003; Mitton \& Donaldson, 2002; Mitton \& Prout, 2004), where resources were allocated depending mainly on the previous year's expenditure with some political and/or demographic modifications (Teng, Mitton, \& MacKenzie, 2007). Such patterns are unlikely to maximise the utilisation of health resources (Birch \& Chambers, 1993), and decision makers from several health systems from across the world expressed their dissatisfaction with such processes, emphasising the need to set priorities based on evidence (Mitton \& Donaldson, 2002; Mitton \& Prout, 2004; Teng et al. 2007). Nevertheless, health decision makers usually struggle to access and utilise available evidence (Smith et al., 2013; Bryan, Williams, \& McIver, 2007). Policy makers usually lack data and are unaware of existing priority setting instruments, while hospital managers usually struggle to maintain the quality of services at low costs, under shrinking budgets and growing demand (Sibbald et al., 2009; Gibson et al., 2004; Mitton \& Donaldson, 2002; Reeleder, Martin, Keresztes, \& Singer, 2005).

With the current economic situation in Kuwait, it is crucial to evaluate the process of priority setting and resource allocation to identify strengths and weaknesses. By studying the attitudes and perceptions of relevant stakeholders about resource allocation, the priority-setting process within healthcare organisations could be improved (Sibbald et al., 2009). Perceptions of decision makers about resource allocation in the Kuwaiti health system have not been previously studied, and hence, are a valuable source of information.

To better understand the process of priority setting and resource allocation in the current health system, a qualitative explorative study of hospital managers in Kuwait was conducted. The objectives of this survey were: 1) to identify the current organisational priority setting and resource allocation practices; 2 ) to determine the strengths and weaknesses of current processes; 3 ) to highlight strategies to improve the current processes; 4) to assess the effects on healthcare system efficiency of two recent policies; sending patients abroad for treatment, and private health insurance for retirees.

\section{Methods}

\subsection{Context}

Health authorities in Kuwait have taken initiatives to cope with the changing landscape. One of these initiatives was to invest in establishing 20 large-scale local healthcare projects worth $\$ 12$ billion with approximately 11,200 additional beds (KLSC, 2016). The budget of the Ministry of Health increased from $\$ 2.9$ billion in the fiscal year $2009 / 2010$ to $\$ 5.8$ billion in the fiscal year 2014/2015 (Ministry of Health [MOH], 2017). The per capita health expenditure increased from $\$ 731$ to $\$ 1,203$ for the same fiscal years $(\mathrm{MOH}, 2017)$. Current healthcare spending in Kuwait is thought to be inefficient because: (a) the government funds services without performing Health Technology Assessments (HTA); (b) the government does not use sophisticated methods of funding, and instead, pays providers through block contracts; (c) expenditure is not transparent because full costing is not used; and (d) budgets for providers are not based on need (Mossialos, Cheatley, Reka, Alsabah, \& Patel, 2018).

In addition to providing health services locally, the Ministry also funds sending Kuwaiti nationals to receive treatment in overseas facilities. This policy has been practiced since the public health service was first established in the 1960s to fill gaps in available health services. Currently however, Kuwait has adequate clinics and hospitals staffed by skilled professionals that provide safe and effective services (World Health Organisation [WHO], 2014). Nevertheless, the practice of sending patients abroad has increased over the last few years. The costs of this policy 
has increased from around $\$ 151$ million in 2007/2008 to around \$306 million in 2013/2014 (MOH, 2014). The number of patients that were sent abroad for treatment increased from 4070 in 2009 to 6973 in 2014 (MOH, 2017). Additionally, suspicions have recently been raised in the Kuwait Times about the costs of this policy (Jouhar, 2017). It was argued that for political reasons, spending on this policy was several times higher than allocated in the budget, funneling resources away from patients in need (Jouhar, 2017).

Another national initiative was to attempt to improve the overall quality of services by increasing the involvement of the private sector in health provision (KLSC, 2016). Of the first steps taken was the procurement of private health insurance for retirees. This policy was issued by the parliament in 2014, with provision of services for beneficiaries starting in October 2016 (MOH, 2017). The contract was valued around \$273million for the first year, with a cost of around \$2,550 per person (MOH, 2017). Initially, the Ministry of Health expected 107,000 beneficiaries but the actual number that utilised this service was 114,952, and was expected to increase to 125,000 for the second year contract $(\mathrm{MOH}, 2017)$. The service network is comprised of 120 local health practices and more than 800 doctors, providing inpatient services, chronic and specialised outpatient services, dental services, obstetric services and others.

This study was conducted by interviewing hospital managers in Kuwait from the public and private sectors. These managers are the communication link between front line professionals (i.e. physicians and nurses) and decision makers (i.e. undersecretary and assistant undersecretaries in the public health sector, and board members in the private health sector).

\subsection{Study Participants and Data Collection}

This is a qualitative study using semi-structured, face-to-face interviews, consisting of open-ended questions, with hospital managers in Kuwait. Initially, an information sheet was sent to all potential participants, inviting them to take part and explaining the aim of the study. Participants who agreed to take part in the study scheduled an interview date, and provided a written consent at the start of the interview. An interview guide was developed, and was mostly adapted from previous surveys (Otim et al., 2014; Smith et al., 2013; Mitton \& Donaldson, 2002; Mitton \& Prout, 2004; Teng et al., 2007). The survey was supplemented with additional questions about healthcare resource allocation policies in Kuwait. An initial mock interview was carried out with a researcher in the public health field, and feedback was drawn from this interview to refine following interviews. Additionally, as data analysis continued and the the focus became clearer, the content of the interview guide evolved. The interview guide included 16 open-ended questions that covered five major sections, which were asked to each respondent. These sections were related to decision making in hospitals, the current process of setting priorities and allocating resources in hospitals, the assessment of the current process, the allocation of resources for sending patients abroad for treatment, and the opinions on the policy of private health insurance for retirees (interview guide, Appendix 1).

After obtaining the permission of the participants, the interviews were audiotaped and written notes were taken during the interviews. All interviews were transcribed, verbatim. The interviews were conducted in English by the first researcher and ranged from 30 minutes to 70 minutes. They took place between mid-April to mid-July 2017.

Twenty health managers from the public and private sectors in Kuwait were approached to take part. Six declined and 14 participated. Personal data of hospital managers were collected such as their nationality, their role in their organisation and length of service, involvement in priority setting and/or resource allocation, and whether they had any educational qualification in management.

\subsection{Data Analysis}

By adapting methods from other studies (Mitton \& Donaldson, 2002; Teng et al., 2007) content analysis was used for the interview transcripts, coding each line of the transcripts. The codes were refined several times for consistency during the analysis process. The data wes then categorised into meaningful concepts related to the subject. By using constant comparison, major themes (e.g. 'resource management') and sub-themes (e.g. 'centralised resource allocation') were developed, and all data wes analytically categorised and compared until no new categories were identified. To support the described concepts, key quotes from participants are included.

\subsection{Research Ethics}

The study received ethics approval from UCL Research Ethics Committee (9633/001) and the Standing Committee for Coordination of Medical Research in the Kuwaiti Ministry of Health (Meeting number 5/2016). Written informed consent was obtained from each participant before starting the interviews. The data was treated with confidentiality and was only accessible to the researcher. 


\section{Results}

In total, the views of nine hospital directors, four Chief Executive Officers (CEOs), and one Chief Financial Officers (CFO) within the Kuwaiti healthcare system are presented. The demographics of the participants are shown in Table 1. Public sector priority setting and resource allocation processes differed from those in the private sector, particularly in the structure of the executive management. Therefore, the persons involved in the process also varied between the two groups.

Table 1. Sample characteristics

\begin{tabular}{|c|c|c|}
\hline \multirow{2}{*}{ Gender } & Females & $14.3 \%$ \\
\hline & Males & $85.7 \%$ \\
\hline \multirow{4}{*}{ Age (in years) } & $<40$ & $7.1 \%$ \\
\hline & $40-49$ & $50 \%$ \\
\hline & $50-59$ & $35.7 \%$ \\
\hline & $\geq 60$ & $7.1 \%$ \\
\hline \multirow[t]{2}{*}{ Nationality } & Kuwaiti & $71.4 \%$ \\
\hline & Non-Kuwaiti & $28.6 \%$ \\
\hline \multirow{4}{*}{ Hospital type } & Public (secondary) & $21.4 \%$ \\
\hline & Public (tertiary) & $28.6 \%$ \\
\hline & Private & $42.9 \%$ \\
\hline & Military & $7.1 \%$ \\
\hline \multirow{4}{*}{ Professional background } & Medical & $64.3 \%$ \\
\hline & Dentistry & $7.1 \%$ \\
\hline & Administrative & $21.4 \%$ \\
\hline & Other & $7.1 \%$ \\
\hline \multirow{3}{*}{ Role } & Hospital director & $64.3 \%$ \\
\hline & CEO & $28.6 \%$ \\
\hline & $\mathrm{CFO}$ & $7.1 \%$ \\
\hline \multirow{2}{*}{ Higher degree in hospital management } & Yes & $64.3 \%$ \\
\hline & No & $35.7 \%$ \\
\hline \multirow{5}{*}{ Total experience (in years) } & $<15$ & $7.1 \%$ \\
\hline & $15-19$ & $28.6 \%$ \\
\hline & $20-24$ & $42.9 \%$ \\
\hline & $25-29$ & $14.3 \%$ \\
\hline & $30 \leq$ & $7.1 \%$ \\
\hline \multirow{4}{*}{ Years in managerial role } & $<5$ & $21.4 \%$ \\
\hline & 5-9 & $14.3 \%$ \\
\hline & $10-14$ & $35.7 \%$ \\
\hline & $15 \leq$ & $28.6 \%$ \\
\hline
\end{tabular}

* CEO: Chief Executive Officer; CFO: Chief Financial Officer.

\subsection{Current Processes of Setting Priorities}

The hospital board, accreditation committee and other committees in the hospital participate in the process of allocating resources in public hospitals. Managers from this sector stated that clinical services are always 
considered as priority when compared to other services when allocating resources in their hospitals. It was found that the decision of heads of clinical departments dictated this process. Participants all explained that their organisations had strategic plans that were approved by hospital boards, after undergoing a complex process (Table 2). Most priorities are derived from these strategic plans. Most participants believed that the current process within their organisations was democratic and fair since it involved both medical and administrative staffs, who are believed to have knowledge and experience. Priorities are set according to their importance, and resources allocated according to the needs of clinical departments.

\subsection{Evidence-Based Decisions}

Health managers mentioned useful methods and data sources they use to assist them with priority setting and resource allocation. They consulted internal statistics from previous years and the annual health report published by the Ministry of Health. Only 3 of 14 felt that the use of this information was limited, and only 2 felt the system was not evidence based, and lacked timely and accurate data (Table 2). Additionally, national demographic reports, that assess the needs of indigenous communities, and international reports (i.e. WHO) were mostly used in the process. Feedback in the form of suggestions or complaints from staff, patients and their families were used in adjusting priorities in order of importance. Some public hospital directors claimed the use of risk management reports and the Kuwait Cancer Registry in the process of priority setting. Other managers from the private sector stated that they performed market analyses to identify emerging trends in healthcare in order to guide them in setting the priorities of their organization. One manager explained:

We have a statistics department in the hospital, which falls under the medical records department. They provide us with some information that we try to rely on when determining our needs, like manpower for example. We also use the annual report that is published by the Ministry of Health... It gives you information about bed turnover, bed capacities, number of beds per population... etc. we also have Kuwait Cancer Registry, which is unique to our country. This office provides us with an annual report that is distributed to the whole country, and gives us the statistics of cancer in Kuwait. We use information from all these sources to identify our needs, shortages, and priorities in terms of manpower and equipment. (Public hospital manager 6)

The process of allocating resources across a hospital in the private sector had some differences when compared to the public sector. This process was dependent on the feasibility of the project in hand, the availability of resources, and the type of resources needed. Some participants stated that, by relying on their knowledge and experience, they try to forecast the market needs and then try to meet them. Resources are usually targeted to specialties that are believed to be competitive in their field, or towards services that are believed to be prerequisites to more advanced services. One respondent mentioned that they were using what is called a service line management approach (Note 1) where they focus on three or four service lines (i.e. orthopedics and spine surgeries), have a champion in each of these lines, and provide these champions with their their own budget. Another respondent explained that they allocated their resources according to different seasons of the year. He stated:

We monitor the seasonal fluctuations and divide resources accordingly. For example, in Kuwait during Ramadhan, we have low foot traffic during daytime. That's why I decrease my manpower in the morning shift, and increase it in the night shift, and because they are fasting, they are happy with this arrangement. So we do it because of internal medical reasons, seasonal fluctuations, and festival seasons. (Private hospital manager 4)

In the public sector, most hospital managers stated that ministerial decrees from higher authorities in the Ministry of Health and recommendations from the accreditation report influence the current process of priority setting. They explained that the allocation of resources was even more complicated than the process of priority setting. They stated that despite the flexibility of distributing resources within the hospital, the process was mostly centralised and they had limited authority over the budget allocated for their hospitals. They described that they had a great degree of control over the procurement process and that most purchasing requests for equipment were accepted. On the other hand, they expressed that the allocation of human resources had a different process.

Alternatively, increasing the organisation's profits and efficiency were the main drivers of priority setting in the private sector. Despite that, most health managers from the private sector emphasised their efforts in balancing the quality and efficiency of the services their organisations provide. They also explained that introducing hospital information systems and other technologies are amongst their priorities. 
Table 2. Summary of the findings regarding the current process of setting healthcare priorities

\begin{tabular}{|c|c|c|c|c|c|c|c|c|c|c|c|c|c|c|c|c|}
\hline & & & & & & Indi & vidus & $1 \mathrm{~Pa}$ & ticip & ants & & & & & & Total \\
\hline \multirow{4}{*}{ General } & $\begin{array}{l}\text { Resources allocated according to } \\
\text { clinical needs }\end{array}$ & $\mathbf{X}$ & $\mathbf{X}$ & $\mathbf{X}$ & $\mathbf{X}$ & $\mathbf{X}$ & & $\mathbf{X}$ & & & $\mathbf{X}$ & $\mathbf{X}$ & $\mathbf{X}$ & $\mathbf{X}$ & & 10 \\
\hline & $\begin{array}{l}\text { Relies on previous needs and } \\
\text { MOH's annual report }\end{array}$ & & $\mathbf{X}$ & $\mathbf{X}$ & $\mathbf{X}$ & $\mathbf{X}$ & $\mathbf{X}$ & $\mathbf{X}$ & $\mathbf{X}$ & $\mathbf{X}$ & $\mathbf{X}$ & & & $\mathbf{X}$ & & 10 \\
\hline & $\begin{array}{l}\text { Is mainly performed by hospital } \\
\text { board \& accreditation committee }\end{array}$ & $\mathbf{X}$ & & $\mathbf{X}$ & $\mathbf{X}$ & $\mathbf{X}$ & $\mathbf{X}$ & & $\mathbf{X}$ & & & $\mathbf{X}$ & $\mathbf{X}$ & $\mathbf{X}$ & $\mathbf{X}$ & 10 \\
\hline & $\begin{array}{l}\text { Use research, international } \\
\text { reports, \& stakeholders feedback }\end{array}$ & $\mathbf{X}$ & $\mathbf{X}$ & $\mathbf{X}$ & & & $\mathbf{X}$ & & $\mathbf{X}$ & $\mathbf{X}$ & $\mathbf{X}$ & $\mathbf{X}$ & & & $\mathbf{X}$ & 9 \\
\hline \multirow{4}{*}{ Strengths } & $\begin{array}{l}\text { Process is simple, systematic, } \\
\text { comprehensive and democratic }\end{array}$ & $\mathbf{X}$ & & $\mathbf{X}$ & $\mathbf{X}$ & & $\mathbf{X}$ & $\mathbf{X}$ & $\mathbf{X}$ & $\mathbf{X}$ & & & $\mathbf{X}$ & & & 8 \\
\hline & $\begin{array}{l}\text { Those in charge had knowledge, } \\
\text { experience and communication }\end{array}$ & $\mathbf{X}$ & & $\mathbf{X}$ & $\mathbf{X}$ & & & & $\mathbf{X}$ & $\mathbf{X}$ & & $\mathbf{X}$ & & & & 6 \\
\hline & $\begin{array}{l}\text { Follows the organisation's } \\
\text { strategic plan }\end{array}$ & $\mathbf{X}$ & $\mathbf{X}$ & $\mathbf{X}$ & $\mathbf{X}$ & & $\mathbf{X}$ & & $\mathbf{X}$ & & & & & & & 6 \\
\hline & $\begin{array}{l}\text { Process is dynamic, agile, \& } \\
\text { flexible * }\end{array}$ & & & $\mathbf{X}$ & $\mathbf{X}$ & & & $\mathbf{X}$ & & $\mathbf{X}$ & $\mathbf{X}$ & & & $\mathbf{X}$ & & 6 \\
\hline \multirow{8}{*}{ Weaknesses } & $\begin{array}{l}\text { Slow, centralised, \& bureaucratic } \\
* * \text { Hospital managers had limited } \\
\text { autonomy }\end{array}$ & $\mathbf{X}$ & $\mathbf{X}$ & $\mathbf{X}$ & $\mathbf{X}$ & $\mathbf{X}$ & $\mathbf{X}$ & $\mathbf{X}$ & & & & $\mathbf{X}$ & $\mathbf{X}$ & & $\mathbf{X}$ & 10 \\
\hline & Leaders lack administrative skills & $\mathbf{X}$ & $\mathbf{X}$ & & & $\mathbf{X}$ & $\mathbf{X}$ & $\mathbf{X}$ & & $\mathbf{X}$ & & $\mathbf{X}$ & & & & 7 \\
\hline & $\begin{array}{l}\text { Overspending incentivised } \\
\text { because efficiency is not rewarded }\end{array}$ & $\mathbf{X}$ & & & & $\mathbf{X}$ & & $\mathbf{X}$ & & & & & & & & 3 \\
\hline & $\begin{array}{l}\text { Limited use of health information } \\
\text { systems esp. in public sector }\end{array}$ & $\mathbf{X}$ & $\mathbf{X}$ & & & $\mathbf{X}$ & & & & & & & & & & 3 \\
\hline & Not evidence-based & & $\mathbf{X}$ & & & & & & & & $\mathbf{X}$ & & & & & 2 \\
\hline & Lacks timely $\&$ accurate data & & $\mathbf{X}$ & & & & & & & & $\mathbf{X}$ & & & & & 2 \\
\hline & $\begin{array}{l}\text { Reactionary process follows } \\
\text { crises }\end{array}$ & $\mathbf{X}$ & $\mathbf{X}$ & & & & & & & & & & & & & 2 \\
\hline & $\begin{array}{l}\text { Public not aware of the } \\
\text { importance of some services }\end{array}$ & $\mathbf{X}$ & $\mathbf{X}$ & & & & & & & & & & & & & 2 \\
\hline
\end{tabular}

* especially in the private sector, **especially in the public sector.

\subsection{Strengths and Weaknesses of the Current Process of Priority Setting}

\section{Strengths:}

Participants had mixed opinions about whether their process of priority setting was working well or not, and they have identified both strengths and weaknesses in the current process (Table 2). Eight of fourteen managers felt that the process was simple, systematic, comprehensive and democratic (all stakeholders are involved). Six mentioned that team members who were in charge of this process had knowledge and experience, good communication, and support from their superiors. Additionally, they believed that priorities are usually extracted from the organisation's strategic plan. Another common perception was that the current process had good outcomes and is accredited for good practice. One participant explained:

We have our experience, which is a major strength. We have our colleagues that are very well educated, experienced, and updated in their fields. We have continuous communications with them. These are all strengths that help us identify our priorities. (Public hospital manager 3)

There were some differences in opinions between public and private sector responses regarding the strength of the 
process. In the public sector, it was believed that their big budgets and the absence of competition over resources among public hospitals was an area of strength. One respondent stated that he enjoyed a degree of flexibility in the internal distribution of resources. Another explained that not having any complaints from the staff regarding the current process is a positive sign of compliance.

In the private sector, it was believed that their process is more dynamic, agile, and flexible, in that it could cope with sudden internal and/or external changes. Additionally, this was thought to allow for continuous monitoring and refinement. Some managers explained that their organisations provided training courses for priority setting, and that was a point of strength. A manager stated:

We are very agile. We change courses quite easily. Healthcare is an extremely dynamic industry, with many complex players. We have to always be ready to adjust operations when things change. (Private hospital manager 1)

\section{Weaknesses:}

Participating managers also highlighted a number of weaknesses in the current process of priority setting and resource allocation (Table 2). They complained that the process of setting priorities is not entirely in the control of hospital managers, which sometimes created conflicting priorities between the hospital management and the Ministry of Health. Ten of fourteen managers stated that the process was slow, centralised, and overly bureaucratic. This is believed to be due to the rigid structure of the public healthcare sector, the lack of autonomy for hospital managers, and that decision makers at high levels in the ministry are overwhelmed. Most participants emphasised that they did not have any control over the hospital's budget and did not know the financial resources the hospital is entitled to. This problem was amplified lately because of budget cuts in recent years, which was aggravated by expensive government policy of sending patients abroad for treatment. They also added that they had no control over recruitment or re-allocation of administrative employees, which resulted in assigning employees in jobs that were not in line with their qualifications. Additionally, they believed that frequent rotation of managers between hospitals created shortcomings in the process of priority setting because there wasn't enough time to execute plans. There was a prominent perception that the promotional scheme for administrative staff was unclear, and that there was lack of some important administrative departments (i.e. human resources) in public hospitals. The lack of such departments has created some problems for hospital managers such as a vague picture of administrative training requirements for staff. Participants also mentioned that the absence of health information system and other technologies as a weakness of the current process of priority setting. One manager explained:

One of our major problems is that we don't directly control our budget. We are allocated some resources, and as I have hinted earlier, we can request additional funds for bigger projects, if that was approved by the higher chain of command. We do suffer from certain problems in the allocation process. There is slowness in responding to our needs and requests. There is a lot of bureaucracy and paperwork that delay, at times, our projects. (Public hospital manager 1)

Another point that was raised by managers was the shortage of professional staff in the region, which was emphasised by participants from the private sector since there were more limitations on this sector in the recruitment process of expatriate professionals. The lack of administrative skills of both medical and administrative leadership was identified as weakness of the current process by half of the participants (Table 2). Some respondents added that providing administrative training is both difficult and time consuming. One hospital manager explained:

We have some constraints that are mainly related to recruitments. When we want to expand, it is not easy to recruit qualified staff. There is limited supply of professionals in the local market, so we go abroad, and this raises the problem of selecting the people. Additionally, the process takes a long time. (Private hospital manager 2)

It was mentioned that some requirements of clinical departments as well as some patients' demands were unrealistic, and are sometimes not in line with the general plan of the hospital. The majority of respondents explained that the incentives between physicians and the administration were not aligned, with clinical departments focusing on the quality of services while administrations focus on efficiency. Due to the perceived superiority of clinical departments in decision-making, incentives to overspend were created because efficiency is not rewarded. Additionally, respondents complained of the lack of performing business cases before purchasing medical equipment. One respondent explained:

We do rely on information and requests from different departments, and as you understand, those departments are in competition for resources. So at times, the demands are unrealistic... at times, the demands don't meet the general plan of the organisation... they view something as very important to their department while it is not a 


\section{priority for the whole organisation. (Public hospital manager 1)}

Contradicting the general opinion that the process utilizes informed an qualified people to make decisions, two managers critisised the lack of timely and accurate data, important for setting priorities. This caused a weakness in long-term vision, and therefore, decisions in allocating resources were reactionary rather than proactive. These same two felt that there was a lack of research activity, resulting in 'non-scientific' or 'intuitive' decisions. They added that discrepancies between public announcements and actual practices of the Ministry of Health creates mistrust in public announcements from high officials. The following is an explanation of one of the managers:

There is a lot of intuition rather than numbers, because as we said, there is a lack of accurate and timely data... You use some components of proper data, but you are still missing other types of data that are required to make proper decisions... So, because of the lack of a lot of variables, the decisions are made based on a mixture of some data and some feelings, which are based on experiences and knowledge of the market. (Private hospital manager 1)

Several respondents explained that there was a general sense of entitlement amongst Kuwaiti Nationals, and that the government focused continually on meeting public demand. Furthermore, the lack of public awareness of the importance of some services was perceived as one of the weaknesses in the current process of resource allocation. It is believed that this has resulted in a continuous demand for the availability of medications as a top priority. There was a general belief that hiring good doctors would be sufficient to improve the system. One participant said:

Despite all the efforts that are being put into the service, patients are still not satisfied. Patients have a sense of entitlement that the service should be delivered to them at the time of need, with the highest quality, without waiting nor any responsibility on their side. Don't get me wrong. Patient satisfaction is very important, and patients are the center of the service that we are providing. (Public hospital manager 2)

\subsection{Strategies to Improve the Current Process}

Most respondents from both sectors stated that they rely on the annual (operational) plan and the increase in patient volumes in making decisions to allocate resources across their organisations (Table 2). The process was believed to be unclear in the public sector.

The most prominent suggestion for improvement, favored by 12 of the 14 participants, was that the use of economic principles and/or evidence from economic evaluation could improve the process of priority setting (Table 3). The necessity for using such principles arose from the increasing demand for health services, which lead to the conclusion that the current financing system is not sustainable. Respondents emphasised that the use of such tools would increase the efficiency of the system by better utilisation of limited resources. This would be achieved by increasing the awareness of clinical staff about the need for health technology assessment for medical equipment before requesting them, which would ultimately lead to better utilisation of such equipment. They added that the use of such principles would provide evidence for more informed strategic planning, provide performance benchmarks of different health organisations, and decrease the waste of resources. This would ultimately improve the overall performance of hospitals. One manager argued:

The optimum condition for me is to apply cost effectiveness analysis. We should forecast the patient load on this required device, and how this device would improve our efficiency. I can't invest 0.5 million KD on a machine that would benefit only three patients a year. Such economic evaluation would really improve our efficiency. (Public hospital manager 2)

Some proposed strategies for improvement recommended general changes in the health system. Six respondents wanted legislative changes in the Laws of Civil Services that would improve the process of recruiting and managing national or expatriate professionals. These changes were also believed to increase the availability of professional talents. Five respondents requested changes in the system to increase efficiency and decrease bureaucracy. Decentralising the system by giving managers more autonomy (i.e. more involvement in the procurement process and more control over services contracts such as catering and maintenance) and control over their hospital's budget were proposed recommendations for improvement. The availability of a clear and well-communicated national health strategic plan was mentioned by four of the participants as an important step. Other recommendations were to increase the flexibility in resources re-allocation. Four felt that they needed more political support and less interference to improve the process of priority setting. One participant emphasised the importance of decreasing the interference of higher authorities in transferring staff between hospitals to improve resource allocation. Another suggested that allowing public hospitals to compete for the available resources would improve the process of priority setting. A hospital manager explained: 
Hospital directors should have more authority over the budget. We also need to change the legislations regarding employment... change the laws of the Bureau of Civil Service. I am forced to employ people for public relations without having the correct requirements, for example. The Ministry of Health interferes with our contracts as well, such as catering, security and maintenance. The services are poor. (Public hospital manager 2)

Four managers emphasised the importance of accurate and timely data to overcome some of the weaknesses of the current process. The use of health information systems was believed to assist in improving the quality and utilisation of data, and most believed that the process was based on sound decisions made by the appropriate people, based on data (Table 2). Some managers explained that joining an accreditation programme would improve the current process of priority setting in that it would provide approved metrics to measure the performance of the hospital. One stated:

One thing is that, at different levels, we need to get to a point where we make informed decisions. A lot of our decisions are not informed... at times they are reactionary... at times they are based on non-factual feedback... based on biased perceptions. First of all, we have to be good at gathering information ... to have approved metrics to measure the outcomes and the quality of the service. Once we achieve that, and we have the correct healthcare quality indicators, then we can move based on them. At our organisation, we are trying to improve the service by introducing accreditation to the system, because we view it as a tool to help us streamline work at our organisation. Also, it will help us set priorities within the organisation. (Public hospital manager 1)

Table 3. Strategies to improve the current process

\begin{tabular}{|c|c|c|c|c|c|c|c|c|c|c|c|c|c|c|}
\hline & Ind & ivid & al $\mathrm{P}$ & rticil & pants & & & & & & & & & Total \\
\hline $\begin{array}{l}\text { Use economic principles and/or economic } \\
\text { evaluation }\end{array}$ & $\mathbf{X}$ & $\mathbf{X}$ & $\mathbf{X}$ & $\mathbf{X}$ & $\mathbf{X}$ & $\mathbf{X}$ & $\mathbf{X}$ & $\mathbf{X}$ & $\mathbf{X}$ & $\mathbf{X}$ & $\mathbf{X}$ & & $\mathbf{X}$ & 12 \\
\hline $\begin{array}{l}\text { Laws that would ease recruiting \& manage } \\
\text { national or expatriate health professionals }\end{array}$ & $\mathbf{X}$ & $\mathbf{X}$ & & $\mathbf{X}$ & $\mathbf{X}$ & $\mathbf{X}$ & & & $\mathbf{X}$ & & & & & 6 \\
\hline $\begin{array}{l}\text { Improve administrative skills of hospital } \\
\text { managers }\end{array}$ & $\mathbf{X}$ & $\mathbf{X}$ & $\mathbf{X}$ & & & & & & & & & $\mathbf{X} \mathbf{X}$ & & 5 \\
\hline $\begin{array}{l}\text { More autonomy for managers by } \\
\text { decentralisation \& decreasing bureaucracy }\end{array}$ & $\mathbf{X}$ & $\mathbf{X}$ & $\mathbf{X}$ & & $\mathbf{X}$ & & & & & & & $\mathbf{X}$ & & 5 \\
\hline More political support and less interference & $\mathbf{X}$ & $\mathbf{X}$ & $\mathbf{X}$ & & & & & & & $\mathbf{X}$ & & & & 4 \\
\hline $\begin{array}{l}\text { Increase availability of accurate and timely } \\
\text { information }\end{array}$ & $\mathbf{X}$ & & & $\mathbf{X}$ & & & $\mathbf{X}$ & $\mathbf{X}$ & & & & & & 4 \\
\hline $\begin{array}{l}\text { A clear and well-communicated national } \\
\text { strategic plan }\end{array}$ & $\mathbf{X}$ & $\mathbf{X}$ & & $\mathbf{X}$ & & & $\mathbf{X}$ & & & & & & & 4 \\
\hline Involvement of all stakeholders & & & & & & $\mathbf{X}$ & & $\mathbf{X}$ & & & $\mathbf{X}$ & & & 3 \\
\hline
\end{tabular}

Several proposals emphasised the importance of involving medical staff, administrative staff and patients to improve priority setting. Some participants stated that properly rank priorities, patients' needs should be assessed. It was mentioned that the current process would not improve without developing the sense of belonging for the working staff. Also, it was believed that the process would only improve if there were initiatives to improve the skills of all clinical staff, not only doctors. This would assist in providing a more multidisciplinary medical service. In terms of administration, a unified and systematic process of priority setting for all public hospitals was supported. Additionally, providing hospital managers with a clear job description would be beneficial. Having the appropriate academic qualifications prior to employment and providing better training were believed to improve the skills of administrative staff. A manager emphasised:

You have to have an active team with the right dynamics. All other problems could be solved if you have the right team. You have to develop the sense of belonging in your employees. This is the main foundation. (Public hospital manager 8)

Some respondents proposed improvements involving relations among organisations. One recommendation was to increase public/private partnership and the avoidance of duplication of services between the two sectors. Other managers thought that improving the communication between public hospitals and partnering with other 
institutions (i.e. NGOs) would improve the availability of resources. One manager explained this:

We know that we don't have all the talent and knowledge. So, we try to solve this problem by partnering with key institutions. I think partnerships are key with every possible institution. (Private hospital manager 5)

\subsection{The Policy of Sending Patients Abroad for Treatment}

This study sought to learn health managers' opinions of the policy of sending patients abroad and the effect of this policy on resource allocation in Kuwait. That economics are important to the process is illustrated by the almost universal opinion that decisions should at least consider economic principles (Table 3). The most prominent advantage mentioned by 11 of 14 was intuitive; that the policy increases access to advanced treatments, and treatments for rare conditions that are unavailable in Kuwait (Table 4). One respondent stated that the policy had merits, at least when it was first implemented. Another respondent believed that this policy had no advantage at all. The satisfaction of the public was another advantage of this policy, because it met the immediate needs of patients, promoted patient choice, and offered a degree of privacy and confidentiality. Some managers thought that this policy helped in decreasing the load on the local public health system. This was the response of one of the managers:

It provides health services in centers of excellence for cases that could not be treated locally, like rehab services for example. We are still falling behind in these services. Another strength is that it decreases the load on our hospitals, regardless of the cost. (Public hospital manager 4)

Table 4. Managers' perceptions on the policy of sending patients abroad for treatment.

\begin{tabular}{|c|c|c|c|c|c|c|c|c|c|c|c|c|c|c|c|}
\hline Perceived advantages & & & & & & & & & & & & & & & Total \\
\hline Access to treatments & $\mathrm{X}$ & $\mathrm{X}$ & $\mathrm{X}$ & $\mathrm{X}$ & $\mathrm{X}$ & $\mathrm{X}$ & & $\mathrm{X}$ & $\mathrm{X}$ & $\mathrm{X}$ & $\mathrm{X}$ & & $\mathrm{X}$ & & 11 \\
\hline Public satisfaction & & $\mathrm{X}$ & $\mathrm{X}$ & & & $\mathrm{X}$ & & & $\mathrm{X}$ & & & & & & 4 \\
\hline Decreased national load & & & & $\mathrm{X}$ & & & $\mathrm{X}$ & & & & & & & & 2 \\
\hline \multicolumn{16}{|l|}{ Perceived disadvantages } \\
\hline Inefficiency & $\mathrm{X}$ & & $\mathrm{X}$ & $\mathrm{X}$ & $\mathrm{X}$ & $\mathrm{X}$ & & $\mathrm{X}$ & $\mathrm{X}$ & $\mathrm{X}$ & $\mathrm{X}$ & $\mathrm{X}$ & $\mathrm{X}$ & $\mathrm{X}$ & 12 \\
\hline Reduces trust \& morale & $\mathrm{X}$ & $\mathrm{X}$ & & & $\mathrm{X}$ & & & & & $\mathrm{X}$ & & & $\mathrm{X}$ & & 8 \\
\hline Misuse and corruption & $\mathrm{X}$ & $\mathrm{X}$ & $\mathrm{X}$ & & $\mathrm{X}$ & & $\mathrm{X}$ & $\mathrm{X}$ & & & & & & $\mathrm{X}$ & 7 \\
\hline Increases risks to patients & & & & & & & $\mathrm{X}$ & & & & $X$ & $\mathrm{X}$ & & & 5 \\
\hline Increases inequality & $\mathrm{X}$ & $\mathrm{X}$ & $\mathrm{X}$ & $\mathrm{X}$ & & $X$ & $\mathrm{X}$ & & & $\mathrm{X}$ & & $X$ & & & 3 \\
\hline
\end{tabular}

Most respondents believed that the disadvantages of this policy outweigh its advantages, and some went beyond to explain that it is hurting the system. They described it as a 'bad investment' and 12 of 14 found it to be inefficient (Table 4). These resources included not only treatment expenses, but also flight tickets and living allowances for patients and companions, days absent from work for companions, costs of running health attaché offices in foreign countries, and overtime payments for local doctors who attend committees for sending patients abroad. Some managers shared a belief that the recent budget cuts, which prevented the improvement of some local health sectors, were caused by overspending on sending patients abroad. Managers from private hospitals claimed that this policy affected their sector mainly. One manager expresses his opinion as follows:

Treating patients abroad comes at a very high expense to the national budget. Healthcare is costly whether it was on a local level, and it is definitely more costly when you look at the patients that are treated in Europe or the US. So, there is a substantial amount of money that gets spent outside the cycle of the healthcare system in Kuwait... Also, add to that days lost from work for companions, which usually get full paid leaves as they accompany their ill relatives. So, there, definitely, is a waste of resources at different levels and different areas associated with treating patients abroad. (Public hospital manager 1)

There were other identified disadvantages that affected the care of patients, such as the higher risk on some patients due to travel stresses. Another example was the problem of patients' follow-up, especially after surgical procedures abroad. This is believed to have a negative effect on patients' care since the follow-up is usually disrupted. Not being able to be treated in the company of family and friends was another example. Half the managers from both sectors emphasised that the policy was misused and politically-driven. They added that most specialties are 
available in the country and that most decisions to send patients abroad lacked real medical indications, and that it was corruptly used for tourism (Table 4). One respondent added that such practice created a sense of inequality because not all patients get sent abroad. One manager emphasised:

No two people can disagree that this policy is currently used as a political ticket. No one can deny that the mass majority of this budget is political. (Private hospital manager 1)

Most importantly, most participants explained that the heavy reliance on this policy was publically embarrassing to the local health system, implying incompetence, that decreases public trust in the system. Eight of the healthcare professionals perceived that the national leadership lacks confidence in their talents, which reduces their morale (Table 4). Also, by sending most difficult cases abroad, local talent is not being challenged to thrive and develop skills. Some respondents claimed that the government is not serious about solving this problem. A manager explained:

It is very negative because the policy of sending patients abroad for treatment sends a clear message that the health services here in Kuwait are failing, and that they are not at the required level. So, if you need better medical care, you have to go abroad. This is the message that is being sent. (Public hospital manager 7)

Participants recommended several solutions to overcome the disadvantages of this policy. Some managers believed that the opening of new hospitals that are under construction should result in a decrease in the number of patients being sent abroad for treatment. The majority emphasised the reality of this problem and the government's responsibility to solve it. As an initial step, most respondents believed that the policy should be revised and its cost effectiveness be evaluated. Most respondents preferred redirecting funds earmarked for this policy toward improvements in the local health system. Such investment could involve guidance from international partners to improve local health services by inviting international visiting doctors in the specialties of need and/or participating in formulating a national strategic health plan. Managers from the private sector advised that referring patients to their hospitals would be a better way of utilising health funds. The following was one participant's opinion:

I believe that establishing new hospitals and inviting international professionals to provide their services locally would solve most of the problems that are related to sending patients abroad for treatment. (Public hospital manager 4)

\subsection{Policy of Health Insurance for Retirees}

Improved accessibility to health services by decreasing waiting times was an advantage of this policy noted by eight of the participant (Table 5), which helped in providing timely care for those who were in need. The decrease in the load on the public sector and the shift in health provision towards the private sector are believed to give doctors more time to treat their patients, and ultimately better utilisation of health resources.

There was clear discrepancy in the opinion of managers from the public and private sectors, but ten agreed that the policy decreases the load on the public sector. Few of managers from the public sector believed it was a good policy, while most managers from the private sector thought that it was a good policy. The increased patient load after implementing the policy is believed to influence the opinion of managers from the private sector. A supporter of this policy stated:

I think this was an excellent move. It has expanded the accessibility for the retirees to the private healthcare... The amount that was invested has improved the health of retirees, stimulated the private sector to grow, and ignited the health insurance culture in the country. (Private hospital manager 2)

Managers from the private sector identified most of the advantages of this policy. Of the important advantages was the trust of the government in the private sector. They also claimed that the policy is feasible since treating patients in the private sector was more efficient than treating them in the public sector. As a result, some participants believed that this policy would help in cost containment since it decreases the waste of financial resources. The increase in profit of the private sector after implementing the policy was believed to decrease the risk of investing in the private sector. This would ultimately provide an incentive for growth of the private sector in the form of improving the quality and customer services, and the willingness to expand into more specialised services. This would also lead to improve the public trust in local healthcare. This policy was also believed to increase patient choice, and hence patient satisfaction. Some respondents believed that this policy provides an incentive for the growth of the health insurance market. One respondent explained:

... the government has taken a long-term strategic decision by sending a clear message to the private sector in Kuwait that we trust you, and because of that, we are handing over our most precious segment of our community, 
the retirees, to you... we are betting on your abilities... we want you to grow. (Private hospital manager 3)

Table 5. Managers' perceptions on the policy of providing private health insurance for retirees

\begin{tabular}{|c|c|c|c|c|c|c|c|c|c|c|c|c|c|c|}
\hline \multicolumn{14}{|l|}{ Perceived advantages } & \multirow{2}{*}{$\begin{array}{l}\text { Total } \\
10\end{array}$} \\
\hline Decreases public sector load & $\mathrm{X}$ & & $\mathrm{X}$ & $\mathrm{X}$ & $\mathrm{X}$ & $\mathrm{X}$ & $\mathrm{X}$ & $\mathrm{X}$ & $\mathrm{X}$ & & & $\mathrm{X}$ & $\mathrm{X}$ & \\
\hline Increased access to services & $\mathrm{X}$ & $\mathrm{X}$ & & $\mathrm{X}$ & $\mathrm{X}$ & $\mathrm{X}$ & & & $\mathrm{X}$ & & & $\mathrm{X} x$ & & 8 \\
\hline Reduced wait times & $\mathrm{X}$ & & $\mathrm{X}$ & $\mathrm{X}$ & & $\mathrm{X}$ & & $\mathrm{X}$ & & & & & & 5 \\
\hline Increased patient choice & & & & $\mathrm{X}$ & $\mathrm{X}$ & & $\mathrm{X}$ & $\mathrm{X}$ & & & $\mathrm{X}$ & & & 5 \\
\hline \multicolumn{15}{|l|}{ Perceived disadvantages } \\
\hline Lack of censorship creates duplications & & $\mathrm{X}$ & & & $\mathrm{X}$ & & $\mathrm{X}$ & & $\mathrm{X}$ & $\mathrm{X}$ & $\mathrm{X}$ & & & 6 \\
\hline Lacks clear objectives & $\mathrm{X}$ & $\mathrm{X}$ & & & & & & & & $\mathrm{X}$ & & & & 3 \\
\hline Politically driven & $\mathrm{X}$ & $\mathrm{X}$ & $\mathrm{X}$ & & & & & & & & & & & 3 \\
\hline Creates inequality & $\mathrm{X}$ & $\mathrm{X}$ & $\mathrm{X}$ & & & & & & & & & & & 3 \\
\hline Professionals move to the private sector & $\mathrm{X}$ & & $X$ & & & & & & & & & & & 2 \\
\hline
\end{tabular}

Three respondents from both sectors stated that the objectives of the policy were not clear. Some of them suggested that providing better accessibility to health services, decreasing waiting times, decreasing load on the public sector, increasing patient choice, and minimising cost were amongst the possible objectives of the policy. The majority believed that this policy is the first step towards implementing a national health insurance in the country. When asked about the policy's objective, a manager, emphasizing the lack of economic considerations expressed earlier, answered:

I'm not sure. The objective should have been to minimise cost on the national budget. (Public hospital manager 2)

Several disadvantages of this policy were identified, which were mainly highlighted by managers from public hospitals. Suspicions of political motivations have led to the perception that the policy is not based on a technical foundation and lacked vision, since it was implemented before carrying out a full assessment of its effects. Some participants complained that their opinion on the policy was not taken into consideration. They continue to explain that they only knew about the details of the policy from the media, and that they were not involved at any stage of development. Another disadvantage was the duplication of care, where beneficiaries would utilise services covered by this policy from the private sector and then receive services from the public sector for the same complaint. The lack of censorship is believed to be the reason for such practices. This led to their conclusion that this policy is more costly, strains the health budget, and does not solve current problems. Some added that this policy, just like the policy of sending patients abroad for treatment, would lead to decrease trust in the public health sector. Two believed it would lead to migration of professionals to the private sector, which may lead to failure of the government in running the newly established hospitals (Table 5). Most respondents mentioned that the treatment package provided by this policy is not ideal. One example mentioned was the exclusion of coronary artery catheterization in the first year of the policy. Not including this treatment in the package also raised some ethical issues, since the patient would be receiving radiation twice, once for diagnosis in a private hospital, then again to visualise placement of a catheter during the procedure in the public hospital. Managers from the public sector added that they provide better quality service in their hospitals but patients usually have more tolerance towards the private hospitals, which could be due to better hospitality services. Some participants argued that this policy would bring the disadvantages of private health insurance. One participant mentioned that this policy enforces inequality between sub-groups (only retirees benefit from this policy) and sectors (only private hospitals get paid for their services from the insurance company). A manager complained:

I'm not sure about the main reason behind it. Nobody has been involved in it. Most administrative directors in the Ministry of Health knew about the policy just like the layman ... they read it in the newspapers and the media rather than being involved in the process. (Public hospital manager 7)

Managers mentioned some recommendations to improve the private health insurance policy. Most agreed that the current health financing system is not sustainable, and that social national health insurance is the solution. They added that the current policy needed revision, more regulation and monitoring, to overcome its misuse (i.e. 
duplication of care). There was a belief that after appropriate revision, the policy could contain some costs. Some respondents suggested expanding the treatment package to include the 'real needs' of beneficiaries. Other respondents recommended increasing the number of beneficiaries to include more subgroups, both nationals and expatriates. One manager from the public sector explained that public hospitals should be included in the policy to overcome the misuse in the current policy, as well as to help improve the quality of the services provided by public hospitals.

\section{Discussion}

Despite the importance of priority setting in healthcare and the expansion of this research field (Youngkong, Kapiriri, \& Baltussen, 2009), limited work has been done to study these processes in the Middle East; especially in Kuwait. Our study evaluated the current process of priority setting, the strengths and weaknesses to this process, strategies that could improve the process, as well as two policies that we believe have a great impact on health resources in the county, namely the policy of sending patients abroad for treatment and the policy of private health insurance for retirees.

We identified many similarities to systems in other countries, including the lack of relevant data, the presence of several players with different agendas (i.e. political influence), and the limited use of organised processes for decision-making as obstacles facing priority setting in health systems (Mitton \& Donaldson, 2002; Mitton \& Prout, 2004; Youngkong et al., 2009; Kapiriri \& Martin, 2007). We conclude that there isn't a clear process of priority setting in the current health system, similar to other studies (Ham, 1997; Mitton \& Donaldson, 2002). Most managers stated that the resources in their hospitals were allocated mainly according to the previous years' budget (historical approach), which was similar to priority setting processes in organisations from other high-income countries (Mitton \& Donaldson, 2002; Mitton \& Prout, 2004; Teng et al., 2007). We found that priority setting process was not based on evidence, similar to the findings of Mitton and Patten (2004). This could be related to the limited availability of data that was also a barrier in other settings (Smith et al., 2013; Mitton \& Prout, 2004). Eichler et al. (2004) reported that the awareness of the importance of performing resource allocation in a systematic rather than intuitive manner is increasing.

Mitton and Prout (2004) found that the reactive nature of decision making (crisis) in health systems, political influence and budgetary constraints were weaknesses found in the health system of Western Australia, similar to the opinions of two of our managers. In the midst of the COVID 19 pandemic, many countries are finding, in hindsight, the limitations of reactive measures over proactive ones. Another weakness of the current system supported by ten of our respondents (Table 2), similar to findings of Teng et al. (2007), was that the centralised process led to feelings of disempowerment among managers of public hospitals. The current study also found that because efficiency was not rewarded in the current public system, there was encouragement to overspend, which is in line with Teng et al. (2007), who also identified lack of a formal process of priority setting. The most pervasive finding was that economics need to play a greater role in the system, with 12 respondents calling for an increase in the use of economic principles (Table 3). We found, in agreement with Mitton and Donaldson (2002), that decision makers are often unaware of appropriate tools that would assist them. Respondents from public hospitals did not clearly mention the lack of a formal process, but it could be concluded from their answers that the current process is no different than what was mentioned in the literature.

We also found differences that may be unique to Kuwait. While Teng et al. (2007) showed that physicians roles should be increased, some participants in our study explained that currently, heads of clinical departments (mostly physicians), had unrealistic expectations and an incentive to overspend, because their primary concern is on the quality of service. This is another call for increasing economic considerations, as 7 respondents suggested that leaders lack administrative skills (Table 2); a concern that was also identified by Teng et al. (2007). One respondent recommended management training for physicians to improve priority setting, which was also supported by evidence from Teng et al. (2007). Alternatively, Ham (1997) argues that effective priority setting should include the use of clinical guidelines. There is no doubt, a balance that must be struck, but our results showed that overspending is a greater problem than lack of medical considerations.

The respondents emphasised the importance an available, transparent national health strategy as a first step to improve the process of priority setting, and the importance of this been repeatedly cited (Clark \& Weale, 2012; Guindo et al., 2012; Mitton \& Donaldson, 2002;07). Furthermore, our findings were compatible with other studies in the need for evidence-based information (Otim et al., 2014; Mitton \& Donaldson, 2002; Teng et al., 2007), but in our study, healthcare professionals felt for the most part that the process is led by clinicians that know what they are doing, who care about clinical needs, and use quality information in decision-making (Table 2). Tomson et al. (2005) found that in Lao, better priorities were set to meet real health needs when data from research was 
communicated to and then utilised by health policy makers. Similarly, Mitton et al. (2006) stated that establishing collaboration channels between researchers and health decision makers in British Columbia helped to create a system that was evidence-based, transparent and defensible rather than being tainted by politics.

We, and others (Jan, 2003) document that the use of economic evidence in health policy making was limited, but its use in high income countries has increased (Eddama \& Coast, 2008). Some managers explained that they used evidence from clinical research and protocols in setting their priorities. Several participants mentioned SWOT (a

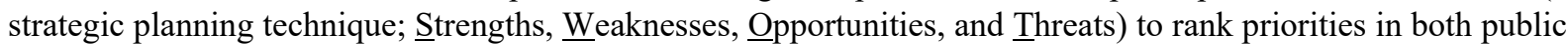
and private hospitals.

The improvement of the current process of priority setting faces several barriers. Our findings agree with Mitton and Donaldson (2003), who found that lack of vision, discontinuity of staff, lack of resources and inadequate training are common barriers to improvements of priority setting processes in health organisations, while effective leadership, commitment to vision and right individual knowledge, skills and attitudes are common facilitators of improvements. Gibson et al. (2004) indicated that running workshops in strategy development for decision makers would assist in the process.

Like Kuwait, other Gulf Cooperation Council (GCC) countries have similar health policies such as sending patients abroad for treatment and private health insurance for their people. Limited studies and/or reports were published to highlight the impact of such policies on health outcomes of these populations. Koornneef et al. (2017) reported that sending patients abroad for medical care amounted to almost a quarter of the UAE's total healthcare expenditure in 2010. In 2013, Abu Dhabi sent over 1400 patients, while Dubai sponsored more than 2700 patients to be treated abroad in 2014 (Koornneef et al., 2017). Similar to our findings, these authors were surprised about the expenditures, in spite of the excellence of the UAE health system. They added that it would be wasteful to routinely send patients abroad for treatment, if the government's ambition to have a world class health system was fully achieved (Koornneef et al., 2017). Our results mirror these opinions.

Regarding mandatory health insurance for nationals and expatriates in Abu Dhabi since 2006, Koornneef et al. (2017) stated that the policy resulted in an increase in costs and insurance claims, which is believed to signal the need for further policy modifications to ensure long-term financial sustainability. They also argued that such increases in costs could be a result of over-use, waste and fraud, and recommended further reforms, which was similar to some participants' opinions in our survey.

Innvær et al. (2002) argued that to increase the use of evidence by healthcare policy makers, researchers needed to establish effective two-way communication with policy makers; deliver brief policy recommendations; ensure that their work is seen as timely, applicable and of high quality; contain effectiveness information; debate that their findings are relevant to current policy and community needs. Nevertheless, while the provision of guidance and potential alternatives is the role of researchers, health decision makers remain responsible for accepting and implementing evidence-based, systematic processes of resource allocation (Ham, 1997; Mitton \& Donaldson, 2002). Mitton and Donaldson (2003) argued that it would be beneficial to recognize specific barriers and plan to overcome them before implementing change in the resource allocation process, as different contexts will require different strategies. So, as other researchers concluded (Ham, 1997), we find no simple resolutions to the dilemma of resource allocation, but recommend that there must be a greater balance toward economic considerations in the process. Predictably, clinicians in charge are neither trained in economics nor administration, and favor clinical needs over economic realities. Although the people making decisions at the hospital level feel that their institutions are making informed decisions, based on well-developed plans, they also want greater autonomy, and less meddling from the government, and especially less political influence.

\section{Limitations}

Our results may be specific to Kuwait, which can be interpreted as both a strength (in Kuwait) and a weakness in generalisation to other contexts. Also, the views of hospital managers could not be generalised to other stakeholders in the health system. Decision makers from the Ministry of Health did not participate in this study because they were overwhelmed with political issues, and a number of them were leaving their jobs. Another limitation is related to the subjective nature of open-ended questions, which includes two types of information bias, and this is common in similar studies (Mitton \& Donaldson, 2002). When analysing the data, it is possible that a coder could report the findings from a biased perspective. Participants not responding truthfully would result in another type of information bias, that we deemed unlikely, since none of them would benefit from deceit (Mitton \& Donaldson, 2002). 


\section{Conclusion}

To the best of our knowledge this study is the first to examine the views of hospital managers on this topic in the Kuwaiti health system. The provision of more accurate and detailed information on the strengths and weaknesses of the current process would help facilitate the improvements. Since decisions are already data-driven, the quality and quantity of data are paramount. It can be concluded that introducing a national health strategy as well as a transparent priority setting process by ensuring that up-to-date and accurate data is available, and that the clinical and administrative staff at hospitals are trained in the necessary economic and management skills, are the measures required to bring about a more effective allocation of resources. Additionally, it is recommended that researchers communicate evidence to policy makers to help them make more informed decisions regarding resource allocation.

As in studies conducted in other countries, our findings are expected to support the need for evidence from economic evaluation and also to encourage discussions on the comparative importance of such evidence. Hence, continuous monitoring and evaluation of the economic impact of health policies, such as sending patients abroad for treatment and private health insurance for retirees, will be required to improve overall health outcomes.

\section{Acknowledgements}

The authors would like to thank Dr. Abdulrahman AlDousari from the Ministry of Health in the State of Kuwait for his assistance on piloting and providing comments on the interview used in this study. The authors would also like to thank the participants for their time. This work was funded by the Ministry of Defence in the State of Kuwait. The views expressed in this paper are those of the authors not the funding body.

\section{Competing Interests Statement}

The authors declare that there are no competing or potential conflict of interests.

\section{References}

Birch, S., Eyles, J., Hurley, J., Hutchison, B., \& Chambers, S. (1993). A Needs-Based Approach to Resource Allocation in Health Care. Canadian Public Policy/Analyse De Politiques, 19(1), 68. https://doi.org/10.2307/3551791

Bryan, S., Williams, I., \& Mciver, S. (2006). Seeing the NICE side of cost-effectiveness analysis: a qualitative investigation of the use of CEA in NICE technology appraisals. Health Economics, 16(2), 179-193. https://doi.org/10.1002/hec.1133

Clark, S., \& Weale, A. (2012). Social values in health priority setting: a conceptual framework. Journal of Health Organization and Management, 26(3), 293-316. https://doi.org/10.1108/14777261211238954

Eddama, O., \& Coast, J. (2008). A systematic review of the use of economic evaluation in local decision-making. Health Policy, 86(2-3), 129-141. https://doi.org/10.1016/j.healthpol.2007.11.010

Eichler, H.-G., Kong, S. X., Gerth, W. C., Mavros, P., \& Jönsson, B. (2004). Use of Cost-Effectiveness Analysis in Health-Care Resource Allocation Decision-Making: How Are Cost-Effectiveness Thresholds Expected to Emerge? Value in Health, 7(5), 518-528. https://doi.org/10.1111/j.1524-4733.2004.75003.x

Gibson, J. L., Martin, D. K., \& Singer, P. A. (2004). Setting priorities in health care organizations: criteria, processes, and parameters of success. BMC Health Services Research, 4(1). https://doi.org/10.1186/1472-6963-4-25

Gibson, J., Martin, D., \& Singer, P. (2005). Evidence, Economics and Ethics: Resource Allocation in Health Services Organizations. Healthcare Quarterly, 8(2), 50-59. https://doi.org/10.12927/hcq..17099

Gibson, J., Mitton, C., Martin, D., Donaldson, C., \& Singer, P. (2006). Ethics and economics: does programme budgeting and marginal analysis contribute to fair priority setting? Journal of Health Services Research \& Policy, 11(1), 32-37. https://doi.org/10.1258/135581906775094280

Guindo, L. A., Wagner, M., Baltussen, R., Rindress, D., Til, J. V., Kind, P., \& Goetghebeur, M. M. (2012). From efficacy to equity: Literature review of decision criteria for resource allocation and healthcare decisionmaking. Cost Effectiveness and Resource Allocation, 10(1), 9. https://doi.org/10.1186/1478-7547-10-9

Ham, C. (1997). Priority setting in health care: learning from international experience. Health Policy, 42(1), 49-66. https://doi.org/10.1016/S0168-8510(97)00054-7

Husain, S., Kadir, M., \& Fatmi, Z. (2007). Resource allocation within the National AIDS Control Program of 
Pakistan: a qualitative assessment of decision makers opinions. BMC Health Services Research, 7(1). https://doi.org/10.1186/1472-6963-7-11

Hutubessy, R., Chisholm, D., \& Edejer, T. (2003). Generalized cost-effectiveness analysis for national-level priority-setting in the health sector. Cost Effectiveness and Resource Allocation, 1(1), 8. https://doi.org/10.1186/1478-7547-1-8

Innvær, S., Vist, G., Trommald, M., \& Oxman, A. (2002). Health policy-makers perceptions of their use of evidence: a systematic review. Journal of Health Services Research \& Policy, 7(4), 239-244. https://doi.org/10.1258/135581902320432778

International Monitary Fund. (2017). Article IV Consultation with Kuwait - IMF Concluding Statement. (2017, November 15). Retrieved from http://www.imf.org/en/News/Articles/2017/11/15/ms111517-2017-article-iv-consultation-with-kuwait-imf-c oncluding-statement

Jan, S. (2003). A perspective on the analysis of credible commitment and myopia in health sector decision making. Health Policy, 63(3), 269-278. https://doi.org/10.1016/S0168-8510(02)00119-7

Jouhar, H. (2017). Cost of Overseas Treatment. Kuwait Times.

Kapiriri, L., \& Martin, D. K. (2007). A Strategy to Improve Priority Setting in Developing Countries. Health Care Analysis, 15(3), 159-167. https://doi.org/10.1007/s10728-006-0037-1

Koornneef, E., Robben, P., \& Blair, I. (2017). Progress and outcomes of health systems reform in the United Arab Emirates: a systematic review. BMC Health Services Research, 17(1). https://doi.org/10.1186/s12913-017-2597-1

Kuwait Life Sciences Company [KLSC]. (2016). Market Overview 2016: Kuwait. United States: IMS Health and Kuwait Life Sciences Company. Retrieved from https://www.tfhc.nl/wp-content/uploads/2017/08/KLSC-IMS-Kuwait-Health-Industry-Report-2016-vF2.pdf

Martin, D., \& Singer, P. (2003). A strategy to improve priority setting in health care institutions. Health Care Analysis, 11(1), 59-68. https://doi.org/10.1023/A:1025338013629

Ministry of Health (MOH). Cost analysis and performance evaluation for government health services. In: Department BaC, editor. Kuwait: MOH; 2014.

Ministry of Health (MOH). Private health insurance for retirees. In: Department of Finance M, editor. Kuwait: MOH; 2017.

Ministry of Health (MOH). Annual Health Report 2015. In: Divisions NCfHIHaVS, editor. Kuwait: MOH; 2017.

Mitton, C., \& Donaldson, C. (2002). Setting priorities in Canadian regional health authorities: a survey of key decision makers. Health Policy, 60(1), 39-58. https://doi.org/10.1016/S0168-8510(01)00190-7

Mitton, C. R., \& Donaldson, C. (2003). Setting priorities and allocating resources in health regions: lessons from a project evaluating program budgeting and marginal analysis (PBMA). Health Policy, 64(3), 335-348. https://doi.org/10.1016/S0168-8510(02)00198-7

Mitton, C., \& Patten, S. (2004). Evidence-based priority-setting: what do the decision-makers think? Journal of Health Services Research \& Policy, 9(3), 146-152. https://doi.org/10.1258/1355819041403240

Mitton, C., \& Prout, S. (2004). Setting priorities in the south west of Western Australia: where are we now? Australian Health Review, 28(3), 301. https://doi.org/10.1071/AH040301

Mitton, C., Mackenzie, J., Cranston, L., \& Teng, F. (2006). Priority Setting in the Provincial Health Services Authority: Case Study for the 2005/06 Planning Cycle. Healthcare Policy | Politiques De Santé, 2(1), 91-106. https://doi.org/10.12927/hcpol..18325

Mossialos, E., Cheatley, J., Reka, H., Alsabah, A., \& Patel, N. (2018). Kuwait Health System Review. London: London School of Economics and Political Sciences (LSE Health). Retrieved from http://00460da.netsolhost.com/downloads/Kuwait\%20Health\%20System\%20Review.pdf

Otim, M. E., Kelaher, M., Anderson, I. P., \& Doran, C. M. (2014). Priority setting in Indigenous health: assessing priority setting process and criteria that should guide the health system to improve Indigenous Australian health. International Journal for Equity in Health, 13(1). https://doi.org/10.1186/1475-9276-13-45

Reeleder, D., Martin, D. K., Keresztes, C., \& Singer, P. A. (2005). What do hospital decision-makers in Ontario, 
Canada, have to say about the fairness of priority setting in their institutions? BMC Health Services Research, 5(1). https://doi.org/10.1186/1472-6963-5-8

Sibbald, S. L., Singer, P. A., Upshur, R., \& Martin, D. K. (2009). Priority setting: what constitutes success? A conceptual framework for successful priority setting. BMC Health Services Research, 9(1). https://doi.org/10.1186/1472-6963-9-43

Smith, N., Mitton, C., Bryan, S., Davidson, A., Urquhart, B., Gibson, J. L., .. \& Donaldson, C. (2013). Decision maker perceptions of resource allocation processes in Canadian health care organizations: a national survey. BMC Health Services Research, 13(1). https://doi.org/10.1186/1472-6963-13-247

Teng, F., Mitton, C., \& Mackenzie, J. (2007). Priority setting in the provincial health services authority: survey of key decision makers. BMC Health Services Research, 7(1). https://doi.org/10.1186/1472-6963-7-84

Tomson, G., Paphassarang, C., Jönsson, K., Houamboun, K., Akkhavong, K., \& Wahlström, R. (2005). Decision-makers and the usefulness of research evidence in policy implementation-a case study from Lao PDR. Social Science \& Medicine, 61(6), 1291-1299. https://doi.org/10.1016/j.socscimed.2005.01.014

Williams, I., \& Bryan, S. (2007). Understanding the limited impact of economic evaluation in health care resource allocation: A conceptual framework. Health Policy, 80(1), 135-143. https://doi.org/10.1016/j.healthpol.2006.03.006

World Bank. (2017). World Development Indicators. Retrieved from http://databank.worldbank.org/data/reports.aspx?source=2\&country=KWT

World Health Orgainization (WHO). Country Cooperation Strategy for WHO and Kuwait 2012-2016. 2014.

Youngkong, S., Kapiriri, L., \& Baltussen, R. (2009). Setting priorities for health interventions in developing countries: a review of empirical studies. Tropical Medicine \& International Health, 14(8), 930-939. https://doi.org/10.1111/j.1365-3156.2009.02311.x

\section{Appendex 1: Interview guide}

\section{The nature of decision-making in the hospitals.}

1. Briefly explain your role in your organisation.

\section{Current process of setting priorities and resource allocation in hospitals.}

2. Can you describe the process of how priorities are set?

3. What sources of information are used in determining short-term and long-term priorities (e.g. burden of disease, economic evidence, accreditation report... etc.)?

4. Once priorities are defined, how are decisions made to divide up the resources across the health sector?

\section{Assessment of the current priority setting process.}

5. In your opinion, do the processes of setting priorities and allocating resources work well?

6. What are the specific strengths of the current approach?

7. What are the shortcomings and problems of the current approach?

8. How could the current process of setting priorities be improved?

9. Do you think the use of economic principles and/or evidence from economic evaluation could improve the process of priority setting?

\section{Resource allocation for sending patients abroad for treatment.}

10. How do you think resources are allocated for sending patients abroad for treatment?

11. What effect do you think sending patients abroad for treatment has on health resources in the country?

12. What are the specific strengths of the policy of sending patients abroad for treatment?

13. What are the disadvantages of sending patients abroad for treatment on the health system? 
Participant's opinions about the newly implemented health insurance for retirees and its effect on resource allocation.

14. What is your opinion of the newly implemented health insurance for retirees' policy?

15. What do you think the main objective of the policy is?

16. What effects do you think it will have on health resources in the country?

\section{Notes}

Note 1. Service-line management involves identifying the different business units, or 'service lines', of an NHS foundation trust and understanding how they contribute to the trust's performance as a whole, allowing clinicians and managers to deliver improvements in quality and productivity at the specialty level. Service-line management aims to ensure more effective use of resources to fund better patient care (GOV.UK, 2014).

\section{Copyrights}

Copyright for this article is retained by the author(s), with first publication rights granted to the journal.

This is an open-access article distributed under the terms and conditions of the Creative Commons Attribution license (http://creativecommons.org/licenses/by/4.0/). 